\title{
Manajemen Pemanenan Kelapa Sawit (Elaeis guineensis Jacq.) di Divisi 2 Bangun Koling Estate, Kotawaringin Timur, Kalimantan Tengah
}

Management Harvesting Oil Palm (Elaeis guineensis Jacq.) In Division 2 Bangun Koling Estate, East Kotawaringin, Central Kalimantan

\section{Ilham Kurniawan dan Adolf Pieter Lontoh*}

Departemen Agronomi dan Hortikultura, Fakultas Pertanian, Institut Pertanian Bogor (Bogor Agricultural University), Jl. Meranti, Kampus IPB Darmaga, Bogor 16680, Indonesia Telp. \& Faks. 0251-8629353 e-mail: agronipb@indo.net.id

"Penulis untuk korespondensi : alfpiton@yahoo.com

Disetujui : 15 Januari 2018 / Published Online 23 Januari 2018

\begin{abstract}
The research conducted in Division 2 Bangun Koling Estate located in Tumbang Koling, Cempaga Hulu District, East Kotawaringin, Central Kalimantan from February until June 2016. This activity intended to enhance knowledge, improve skill, for experiences and also to learn about techniques of cultivation and management of palm. Variable of observation consist of harvest density figures, labor requirements, the capacity of harvesting, harvesting equipment and personal protective equipment, fruit quality, transportation and yield losses. Based on the observations, the results indicated that the management of harvesting palm oil was good but it still need evaluation and improvement in some aspects to obtain optimal production results. The evaluation are result of taxation not describe the actual results of harvesting, use of personal protective equipment still less attention, low harvesting capacity and there are yield losses in the field.
\end{abstract}

Keywords: BGA, harvesting, palm

\begin{abstract}
ABSTRAK
Kegiatan penelitian dilakukan di divisi 2 Bangun Koling Estate yang terletak di Desa Tumbang Koling, Kecamatan Cempaga Hulu, Kabupaten Kotawaringin Timur, Kalimantan Tengah dari bulan Februari hingga Juni 2016. Kegiatan penelitian dilaksanakan untuk meningkatkan pengetahuan, keterampilan kerja, menambah pengalaman serta mempelajari kegiatan budidaya kelapa sawit secara teknis dan manajerial. Pengamatan yang diamati meliputi angka kerapatan panen dan estimasi produksi, kebutuhan tenaga panen, kapasitas panen, alat panen dan alat pelindung diri, mutu buah, transportasi buah, dan kehilangan hasil. Hasil pengamatan yang telah dilakukan menunjukkan bahwa manajemen panen sudah berlangsung secara baik, tetapi perlu ditingkatkan agar didapatkan hasil yang optimal. Evaluasi yang harus dilakukan yaitu hasil taksasi belum menggambarkan hasil realisasi panen, penggunaan alat pelindung diri yang masih minim, kapasitas panen yang masih rendah dan masih terdapatnya losses di lapang.
\end{abstract}

Kata kunci : BGA, kelapa sawit, pemanenan 


\section{PENDAHULUAN}

Komoditi perkebunan memiliki prospek yang bagus sebagai sumber perolehan devisa maupun pajak salah satunya yaitu kelapa sawit (Elaeis guineensis Jacq). Kelapa sawit juga memiliki arti penting bagi Indonesia karena mampu menciptakan lapangan pekerjaan untuk masyarakat. Perkebunan kelapa sawit telah menyebar ke berbagai wilayah Indonesia dengan luas areal yang semakin bertambah setiap tahun. Luas areal mencapai 10.956.231 pada tahun 2014 dengan produktivitas CPO rata-rata 3,6 ton ha-1 (Direktorat Jenderal Perkebunan, 2015).

Peningkatan hasil produksi kelapa sawit dapat dilakukan melalui kegiatan perluasan areal pertanaman, rehabilitasi kebun yang sudah ada atau intensifikasi. Beberapa faktor yang mempengaruhi produktivitas kelapa sawit yaitu iklim, topografi, kondisi tanah, bahan tanam, teknik budidaya tanaman, umur tanaman, jumlah populasi per ha, sistem penyerbukan, sistem koordinasi panen, sistem pengamanan produksi serta sistem premi panen (Pusat Penelitian Kelapa Sawit, 2006).

Teknik budidaya kelapa sawit terdiri atas beberapa kegiatan yaitu pembukaan lahan, penanaman kelapa sawit, pemeliharaan tanaman dan pemanenan. Salah satu teknik budidaya yang sangat penting dalam pengusahaan kelapa sawit adalah kegiatan pemanenan. Pemanenan adalah pemotongan tandan buah segar dari pohon hingga pengangkutan ke pabrik (Pusat Penelitian Kelapa Sawit, 2006). Kegiatan panen ini membutuhkan teknik khusus untuk mendapatkan hasil yang berkualitas. Hasil panen utama dari kelapa sawit adalah buah kelapa sawit yang berupa tandan buah segar (TBS). TBS diolah di pabrik kelapa sawit untuk mendapatkan minyak nabati.

Kegiatan panen terdiri dari persiapan sebelum panen, pelaksanaan panen, evaluasi panen, serta pengangkutan buah. Persiapan panen yang baik akan memperlancar pelaksanaan panen. Persiapan ini meliputi ketersediaan tenaga kerja, peralatan, pengangkutan, pengetahuan tentang kerapatan panen dan sarana panen (Fadli et al., 2006). Pelaksanaan panen yaitu kegiatan penurunan buah dari pohon dengan menggunakan kriteria panen yang berlaku. Kriteria panen merupakan salah satu faktor yang dapat membantu pemanen untuk menentukan buah layak panen. Pelaksanaan panen perlu memperhatikan beberapa kriteria tertentu sebab tujuan panen kelapa sawit adalah untuk mendapatkan rendemen minyak yang tinggi dengan kualitas minyak yang baik (Fauzi et al.,
2008). Evaluasi panen sangat dibutuhkan dalam kegiatan pemanen. Kegiatan panen yang baik disertai dengan evaluasi terhadap mutu panen. Evaluasi mutu panen dilakukan untuk memperhitungkan potensi kehilangan hasil dan mencegah terjadinya kehilangan hasil. Evaluasi terhadap mutu panen terdiri dari evaluasi mutu hancak dan mutu buah. Pengangkutan buah dibagi menjadi dua, yaitu pengangkutan dari piringan ke tempat pengumpulan hasil (TPH) dan pengangkutan dari TPH ke pabrik. Kegiatan pengangkutan harus dilakukan secepat mungkin untuk menghindari pencurian buah di lapangan dan peningkatan asam lemak bebas. Asam lemak bebas yang tinggi akan mempengaruhi kualitas minyak kelapa sawit (Andoko dan Widodoro, 2013). Keberhasilan panen akan menunjang pencapaian produktivitas tanaman kelapa sawit sebab potensi produksi yang tinggi juga tidak ada artinya jika pengelolaan hasil tidak dilakukan secara optimal.

Kegiatan penelitian ini secara umum bertujuan meningkatkan kemampuan dan pemahaman mahasiswa baik secara teknis maupun manajerial dalam pengelolaan perkebunan kelapa sawit. Secara khusus kegiatan penelitian ini bertujuan untuk mempelajari manajemen pemanenan di perkebunan kelapa sawit.

\section{METODE PENELITIAN}

Kegiatan penelitian dilaksanakan di Divisi 2 Bangun Koling Estate, Kotawaringin Timur, Kalimantan Tengah, yang dilakukan selama empat bulan dimulai dari 5 Februari 2016 sampai 5 Juni 2016. Metode pelaksanaan yang digunakan adalah melaksanakan seluruh kegiatan yang sudah dilaksanakan di perusahaan, baik dengan metode langsung maupun tidak langsung yang bertujuan memperoleh data primer dan sekunder. Metode langsung adalah praktek kerja langsung ke lapang (untuk mendapatkan data), wawancara dan diskusi. Metode tidak langsung dilakukan melalui pengumpulan laporan bulanan, laporan tahunan dan arsip kebun.

Kegiatan penelitian pada bulan pertama adalah bekerja langsung sebagai karyawan harian, menjadi pendamping mandor pada bulan kedua, menjadi pendamping asisten divisi pada bulan ketiga dan keempat. Selama kegiatan berlangsung prestasi kerja dicatat pada jurnal harian. Kegiatan yang dilakukan sebagai karyawan harian adalah mengikuti pekerjaan yang sudah ditentukan waktunya oleh perkebunan seperti pengendalian gulma, pengendalian hama dan penyakit, pemupukan hingga pemanenan. Kegiatan yang 
dilakukan sebagai pendamping mandor adalah menyusun rencana kegiatan harian, menentukan jumlah tenaga kerja, memimpin apel pagi, mengawasi kegiatan yang dilakukan oleh karyawan harian, mengarahkan karyawan, membuat laporan harian mandor dan mengisi administrasi pada tingkat mandor. Mandor yang membimbing selama penelitian adalah mandor 1 , mandor panen, mandor perawatan, mandor pupuk, mandor BSS, krani divisi, krani panen dan krani transpor. Kegiatan yang dilakukan sebagai pendamping asisten divisi (dibawah bimbingan asisten yang ditunjuk) antara lain memimpin karyawan pada apel pagi serta membuat rencana kerja harian dan bulanan.

Pengamatan dan pengumpulan data dalam kegiatan penelitian meliputi data primer dan data sekunder. Data primer didapatkan dari pengamatan secara langsung pada praktik kerja di lapangan, ataupun dengan wawancara kepada pekerja yang bertugas di lapangan maupun kantor kebun. Data sekunder diperoleh dari perkebunan meliputi lokasi dan letak geografis kebun, keadaan tanah dan iklim, luas areal dan tata guna lahan, peta wilayah, peta kebun dan struktur organisasi perusahaan.

Pengamatan yang dilakukan untuk melengkapi data primer yaitu: (1) Angka Kerapatan Panen dan Estimasi Produksi. Pengamatan dilakukan sebanyak tiga kali ulangan dan dilakukan pada satu seksi panen. (2) Kebutuhan tenaga panen. Pengamatan kebutuhan tenaga panen harian dilakukan berdasarkan wawancara dengan asisten divisi serta pengamatan langsung dengan mengamati jumlah pemanen yang ada. Jumlah tenaga panen lalu dibandingkan dengan standar perusahaan. (3) Alat panen dan alat pelindung diri (APD). Pengamatan alat panen dilakukan secara langsung di lapangan dan mencatat seluruh alat bantu yang digunakan pemanen tersebut. Pengamatan APD dilakukan terhadap seluruh pemanen dengan ulangan berupa kemandoran panen. (4) Kapasitas panen. Pengamatan dilakukan terhadap 30 orang pemanen selama satu rotasi panen dengan tujuan membandingkan pada tingkat usia dan lama bekerja. (5) Mutu buah. Pengamatan mutu buah dilakukan selama dua kali rotasi panen dalam satu seksi panen. Jumlah buah yang diamati adalah 100 tandan per satu seksi panen. (6) Kehilangan hasil (losses). Pengamatan dilakukan dengan cara mengamati mutu ancak dan mutu TPH, kemudian dibandingkan dengan standar perusahaan. (7) Transportasi buah. Pengamatan yang diamati adalah jumlah buah yang dikirim, waktu muat, waktu tempuh ke PKS, kecepatan rata-rata, berat muatan, dan jumlah pekerja.
Analisis yang digunakan dalam mengolah data yang diperoleh dari kegiatan magang adalah analisis secara deskriptif dan kuantitatif. Analisis deskriptif digunakan untuk mencari nilai rata-rata dan persentase yang kemudian dideskripsikan dengan pembanding norma baku dan standar yang berlaku di perusahaan ataupun melalui studi pustaka. Analisis kuantitatif dilakukan dengan uji t-student menggunakan software Minitab 16. Uji $t$-student digunakan untuk membandingkan suatu data yang diperoleh

\section{HASIL DAN PEMBAHASAN}

\section{Kondisi Umum}

Bangun Koling Estate (BKLE) terletak di Desa Tumbang Koling, Kecamatan Cempaga Hulu, Kabupaten Kotawaringin Timur, Provinsi Kalimantan Tengah. Secara geografis BKLE masuk kedalam Waktu Indonesia Barat (WIB) dengan letak geografis berada di antara $112.01^{\circ}$ $113.09^{\circ}$ Bujur Timur dan $1.45^{\circ}-1.85^{\circ}$ Lintang Selatan.

BKLE memiliki luas areal sebesar 3183.2 ha, terbagi ke dalam 3 areal yaitu areal yang diusahakan, areal dapat ditanam, dan areal tidak dapat ditanam. Areal yang diusahakan, terdiri dari areal pertanaman kelapa sawit seluas 2529.8 ha dengan tahun tanam 2006 sampai 2011 dan areal prasarana berupa emplasemen seluas 67.1 ha serta jalan dan jembatan 72.4 ha. Pada areal pertanaman BKLE memiliki 3 Divisi, Divisi 1 memiliki luas 811.93 ha, Divisi 2 memiliki luas 860.29 ha, dan Divisi 3 memiliki luas 857.43 ha. Areal yang tidak dapat ditanam memiliki luas 356 ha meliputi tanah desa, bukit, sungai, rawa dan pasir.

BKLE termasuk areal kebun inti, yang menggunakan bibit kelapa sawit varietas tenera yang berasal dari progeni Merihat, Socfindo, Costa Rica, Lonsum dan Papua New Guinea. Jarak tanam yang digunakan adalah $9.2 \mathrm{~m}$ x $9.2 \mathrm{~m}$ x $9.2 \mathrm{~m}$ dengan stand per ha (SPH) 136 tanaman. BKLE mulai berproduksi pada tahun 2009. Produksi dan produktivitas kelapa sawit di BKLE (2011-2015) menunjukkan peningkatan pada setiap tahun (Tabel 1).

Tabel 1. Produksi dan produktivitas panen TBS di BKLE tahun 2011-2015

\begin{tabular}{ccccc}
\hline Tahun & $\begin{array}{c}\text { Luas TM } \\
\text { (ha) }\end{array}$ & $\begin{array}{c}\text { BJR } \\
\text { (kg) }\end{array}$ & $\begin{array}{c}\text { Produksi } \\
\text { (ton) }\end{array}$ & $\begin{array}{c}\text { Produktivitas } \\
\text { (ton ha }^{-1} \text { ) }\end{array}$ \\
\hline 2011 & 2347 & 4.76 & 21892 & 9.33 \\
2012 & 2381 & 6.20 & 32779 & 13.76 \\
2013 & 2414 & 7.52 & 38963 & 16.14 \\
2014 & 2505 & 8.29 & 50110 & 20.01 \\
2015 & 2510 & 9.75 & 58031 & 23.12 \\
\hline
\end{tabular}

Keterangan: TM: tanaman menghasilkan, BJR: berat janjang rata-rata 
Data curah hujan 2011 - 2015 menunjukkan bahwa rata-rata curah hujan di BKLE adalah 3145 $\mathrm{mm}$ tahun $^{-1}$ dengan rata-rata hari hujan 115 hari per tahun dengan 10 bulan basah dan 1.2 bulan kering. Berdasarkan sistem klasifikasi iklim Schmidth - Ferguson, BKLE termasuk kedalam tipe iklim A (sangat basah) dengan nilai $\mathrm{Q}=12 \%$. Kondisi topografi di BKLE yaitu tergolong datar dengan keadaan tanah yang dominan adalah jenis tanah Inseptisol, selain itu di BKLE terdiri atas jenis tanah Ultisol, Inseptisol, Entisol, dan Hitosol. BKLE termasuk pada kelas S3 pada kesesuaian lahan dengan faktor pembatas tekstur tanah berpasir.

\section{Aspek Teknis Pengelolaan Kebun BKLE}

Aspek teknis adalah kegiatan yang dilakukan sebagai karyawan lapangan selama melaksanakan penelitian di BKLE. Kegiatan aspek teknis yang dilakukan meliputi pengendalian gulma secara manual dan kimiawi, pengendalian hama, leaf sampling unit (LSU), soil sampling unit (SSU), pemupukan, black bunch cencus (BBC), hatch hand carry, penunasan pelepah, dan pemanenan.

\section{Angka Kerapatan Panen dan Estimasi Produksi}

Angka kerapatan panen (AKP) adalah perbandingan antara buah matang dengan jumlah tanaman pada luasan sampel yang akan dipanen. AKP didapatkan dari kegiatan taksasi panen yang dilakukan satu hari sebelum panen. AKP akan mengetahui estimasi produksi yang akan didapatkan. Pengamatan dilakukan sebanyak 3 kali per seksi panen (Tabel 2). Berdasarkan pada Tabel 2 didapatkan nilai AKP berkisar 13\% - 18\% dan persentase varian tonase yang berbeda-beda. Pada ulangan 1 dan ulangan 2 didapatkan persentase varian tonase yang cukup tinggi yaitu $26,46 \%$ dan $11,17 \%$, sedangkan pada ulangan 3 didapatkan persentase varian tonase yang sangat baik yaitu $0,95 \%$. Pada ulangan 1 yaitu taksasi yang biasa dilakukan oleh para mandor panen dan mandor satu dengan mengambil tanaman contoh sebanyak 4 pasar rintis didapatkan hasil varian tonase yang tinggi. Hasil varian tonase yang tinggi salah satunya disebabkan oleh pengambilan tanaman contoh yang sedikit sehingga hasil taksasi tidak menggambarkan hasil realisasi panen. Pada ulangan 2 yaitu taksasi dilakukan dengan menggambil tanaman contoh sebanyak 10 $\%$ disetiap blok panen, hasil yang didapatkan persentase varian tonase masih tinggi yaitu telah melewati batas kesalahan 5\%. Hasil taksasi pada ulangan ke 2 masih belum menggambarkan hasil realisasi panen. Pada ulangan ke 3 yaitu pengambilan tanaman contoh sebanyak $10 \%$ dan mewakili blok panen per kemandoran. Hasil yang didapatkan pada ulangan ke 3 sangat baik dengan persentase varian tonase yang kecil sehingga hasil taksasi dapat menggambarkan hasil realisasi panen. Selain itu menurut Miranda (2009) perbedaan hasil dalam estimasi dan realisasi dapat disebabkan oleh tingkat ketelitian saat pengamatan masih rendah atau adanya kesalahan dari pemanen itu sendiri baik pemanenan tandan yang belum memenuhi kriteria matang panen atau buah matang tertinggal di tanaman. Penyelesaian masalah terhadap varian tonase yang tinggi dapat diatasi dengan pengambilan contoh tanaman untuk taksasi yaitu $10 \%$ populasi per blok panen dan mewakili blok panen per kemandoran.

\section{Kebutuhan Tenaga Panen}

Faktor yang harus diperhatikan dalam produksi kelapa sawit adalah tenaga kerja. Tenaga kerja panen adalah salah satu aspek yang dapat menunjang produksi pada suatu kebun. Penentuan tenaga kerja panen harus memperhatikan luas areal, jumlah buah yang akan dipanen, dan kapasitas pemanen. Kekurangan tenaga panen akan menyebabkan produksi yang dihasilkan tidak maksimal, sedangkan kelebihan tenaga kerja akan meningkatkan biaya produksi.

Tenaga pemanen di divisi 2 BKLE terdapat pada 3 kemandoran yaitu kemandoran A dengan pemanen 16 orang, kemandoran $\mathrm{B}$ dengan pemanen 15 orang dan Kemandoran $\mathrm{C}$ dengan pemanen 15 orang. Penetapan tenaga kerja di BKLE divisi 2 tidak ditentukan dengan perhitungan taksasi panen melainkan dihitung dari budget per tahun sesuai dengan kondisi buah yang

Tabel 2. Hasil taksasi produksi dan produksi realisasi Divisi 2 BKLE

\begin{tabular}{ccccccccc}
\hline \multirow{2}{*}{$\begin{array}{c}\text { Seksi } \\
\text { panen }\end{array}$} & $\begin{array}{c}\text { Luas } \\
(\mathrm{ha})\end{array}$ & $\begin{array}{c}\text { AKP } \\
(\%)\end{array}$ & $\begin{array}{c}\text { Produksi } \\
(\text { janjang) }\end{array}$ & $\begin{array}{c}\text { Produksi } \\
(\mathrm{kg})\end{array}$ & AKP $(\%)$ & $\begin{array}{c}\text { Produksi } \\
(\text { janjang) }\end{array}$ & $\begin{array}{c}\text { Produksi } \\
(\mathrm{kg})\end{array}$ & $\begin{array}{c}\text { Varian } \\
\text { tonase } \\
(\%)\end{array}$ \\
\hline 1 & 140.30 & 16.15 & 3243 & 32430 & 18.37 & 3688 & 41010 & 22.97 \\
2 & 164.39 & 15.01 & 3321 & 33525 & 17.60 & 3893 & 37270 & 11.17 \\
3 & 119.73 & 13.62 & 2281 & 26805 & 13.94 & 2334 & 27060 & 0.95 \\
\hline
\end{tabular}


ada di lapangan (buah sedikit, buah normal dan panen raya). Perhitungan tenaga panen dapat dilihat sebagai berikut:

Ditetapkan data produksi 8 bulan sebelumnya:

- Produksi terendah 17 ton, Produksi tertinggi 90 ton, Produksi rata-rata $=50$ ton

\begin{tabular}{|l|l|l|}
\hline$\bullet$ & Luas seksi panen per hari & $=143.38 \mathrm{ha}$ \\
\hline$\bullet$ & Output yang pernah dicapai & $=1514 \mathrm{~kg}$ \\
\hline$\bullet$ & Target per hari & $=116 \mathrm{ton}$ \\
\hline
\end{tabular}

Ketetapan dalam kondisi buah sesuai dengan budget per tahun yaitu:

\begin{tabular}{|l|l|l|}
\hline$\bullet$ & Keadaan buah sedikit & $=143.38 \mathrm{ha}$ \\
\hline$\bullet$ & Keadaan buah normal & $=1514 \mathrm{~kg}$ \\
\hline$\bullet$ & Keadaan buah banyak & $=116 \mathrm{ton}$ \\
\hline
\end{tabular}

Maka kebutuhan pemanen yaitu:

$$
\begin{aligned}
\text { Keadaan buah sedikit } & =\frac{6}{12} \times 116000 \mathrm{~kg} \\
& =58000 \mathrm{~kg} \\
& =\frac{58000 \mathrm{~kg}}{1514 \mathrm{~kg}}=38 \text { tenaga kerja }
\end{aligned}
$$

Keadaan buah normal $=\frac{9}{12} \times 116000 \mathrm{~kg}$

$$
\begin{aligned}
& =87000 \mathrm{~kg} \\
& =\frac{87000 \mathrm{~kg}}{1514 \mathrm{~kg}}=57 \text { tenaga kerja } \\
& =\frac{12}{12} \times 116.000 \mathrm{~kg} \\
& =116000 \mathrm{~kg} \\
& =\frac{116000 \mathrm{~kg}}{1514 \mathrm{~kg}}=76 \text { tenaga kerja }
\end{aligned}
$$$$
\text { Keadaaan buah banyak }=\frac{12}{12} \times 116.000 \mathrm{~kg}
$$

Kebutuhan tenaga panen di divisi 2 BKLE adalah 38 orang pada kondisi buah sedikit, 57 orang pada kondisi buah normal, dan 76 orang pada kondisi buah banyak. Kebutuhan tenaga kerja panen di BGA dilihat berdasarkan produksi 8 bulan sebelumnya, kemudian ditentukan terhadap kondisi buah dilapang termasuk sedikit, normal atau banyak. Pada saat kegiatan penelitian berlangsung kondisi buah di lapang berada pada kondisi buah sedikit tenaga panen yang tersedia yaitu 46 orang, jumlah tenaga kerja di divisi 2 tergolong berlebih. Tenaga panen yang berlebih dimaksudkan untuk mengantisipasi adanya pemanenan yang mengalami ketidakhadiran. Permasalahan ketidak hadiran meliputi sakit, cuti, mangkir dll. Selain itu, menurut Fadli et al. (2006) kelebihan tenaga panen dapat digunakan untuk kegiatan penunasan atau pemeliharaan lainnya. Tenaga panen yang kurang dapat ditutupi dengan penggunaan sistem kerja potong buah 2 (SKP 2). SKP 2 terdiri dari satu orang yang bekerja untuk

Tabel 3. Penggunaan APD pemanen di Divisi 2 memotong buah dan mengangkut buah ke TPH dan satu orang yang bekerja untuk mengutip brondolan (helper panen) (BGA, 2010). Penggunaan helper panen berasal dari tenaga perawatan.

\section{Alat Pelindung Diri dan Alat Panen}

Alat pelindung diri (APD) wajib selalu digunakan oleh setiap pekerja. Penggunaan APD berfungsi untuk meminimalisir terjadinya kecelakaan kerja. Penggunaan APD pemanen Divisi 2 dapat dilihat pada Tabel 3.

APD adalah alat persiapan panen yang harus disediakan oleh perusahaan dengan tujuan untuk memperkecil kecelakaan saat bekerja. Berdasarkan pengamatan terdapat 3 jenis APD yang harus digunakan oleh pekerja pemanen yaitu terdiri dari sepatu boot, helm dan kacamata. Ketersediaan APD di BKLE divisi 2 belum berjalan sepenuhnya, karena perusahaan baru menyediakan sepatu boot dan helm saja, sedangkan untuk kacamata belum dapat disediakan oleh perusahaan. Pengamatan dilakukan terhadap semua pekerja. Penggunaan sepatu boot $82,64 \%$ dan penggunaan helm hanya 21,53 . Keadaan menunjukan bahwa kurangnya kesadaran pemanen terhadap keselamatan kerja. Menurut Suma'mur (1996) setiap APD yang digunakan memiliki fungsi masing -masing, helm berfungsi untuk melindungi kepala dari benturan benda keras seperti tertimpa TBS atau pelepah. Sepatu boot berfungsi menghindari tertusuk duri atau melindungi dari tertusuk alat panen dan kacamata berfungsi melindungi mata dari partikelpartikel kecil yang dapat masuk ke mata, seperti serbuk sari bunga jantan kelapa sawit. Hasil wawancara didapatkan alasan utama pemanen tidak menggunakan APD, yaitu ketidaknyaman penggunaan APD saat bekerja bagi mereka. Solusi terhadap permasalahan penggunaan APD yaitu perlu dilakukan penyuluhan tentang pentingnya penggunaan APD oleh perusahaan untuk para pekerja. Penggunaan APD ini pun dapat menguntungkan bagi perusahaan dan pekerja. Keuntungan yang didapatkan perusahaan adalah berkurangnya biaya yang dikeluarkan untuk biaya pengobatan saat terjadi kecelakaan kerja, sedangkan keuntungan bagi pekerja yaitu berkurangnya resiko terjadi kecelakaan kerja.

\begin{tabular}{ccccc}
\hline \multirow{2}{*}{ Kemandoran } & \multirow{2}{*}{ Jumlah pemanen } & \multicolumn{3}{c}{ Penggunaan APD (\%) } \\
\cline { 3 - 5 } & 16 & Sepatu boot & Helm & Kacamata \\
\hline A & 15 & 81.25 & 31.25 & 0.00 \\
B & 15 & 86.67 & 20.00 & 0.00 \\
C & & 82.00 & 13.33 & 0.00 \\
\hline Rata-rata & & & 21.53 & - \\
\hline
\end{tabular}


Pelaksanaan panen yang baik ditentukan oleh alat panen yang tersedia dengan baik. Perusahaan telah menyediakan alat-alat untuk menunjang pelaksanaan panen sesuai standar dan dibagikan pada setiap pemanen. Setiap alat panen yang disediakan oleh perusahaan memiliki spesifikasi dan kegunaanya masing-masing (Tabel $4)$.

Alat-alat dalam kegiatan potong buah memiliki fungsinya masing-masing (Tabel 4). Penggolongan alat kerja panen dibagi menjadi tiga bagian yaitu alat untuk memotong TBS, alat untuk bongkar muat TBS, dan alat untuk membawa TBS ke TPH (Pahan, 2008). Alat untuk memotong buah terdiri dari dodos dan egrek. Dalam SOP BGA penggunaan dodos digunakan untuk panen pada tanaman kelapa sawit berusia 5 - 8 tahun dengan ketinggian kurang dari $6 \mathrm{~m}$, sedangkan penggunaan egrek digunakan pada tanaman kelapa sawit berusia 9 tahun ke atas dengan ketinggian lebih dari $6 \mathrm{~m}$. Alat untuk membawa TBS ke TPH terdiri dari angkong, gancu, kapak dan karung. Alat untuk bongkar muat TBS yaitu tojok.

Permasalahan yang terdapat di lapang terkait alat panen di divisi 2 BKLE, yaitu permasalahan terhadap alat potong buat. Dodos yang disediakan perusahaan memiliki kualitas kurang baik dan mudah rusak, sehingga para pemanen harus mengeluarkan biaya lebih untuk membeli dodos dengan kualitas yang terbaik agar dapat menunjang pekerjaannya. Egrek belum tersedia secara keseluruhan hanya tersedia sebagian saja, sehingga ketika pemanen memasuki blok-blok dengan tanaman kelapa sawit tinggi maka waktu pemanenan akan semakin lama karena ketersediaan egrek yang terbatas. Pemanen secara bergantian menggunakan egrek. Permasalahan yang terdapat pada alat pengangkutan TBS ke TPH yaitu ban angkong yang bocor saat evakuasi buah sedang berlangsung, sehingga pemanen sulit untuk mengeluarkan buah dari dalam blok. Karung untuk alas brondolan terkadang tidak berstandar atau tidak berjahit dan jumlahnya yang terbatas sehingga pemanen kesulitan untuk menaburkan brondolan hasil kutipannya. Kendala yang sering ditemui pada alat panen tersebut dapat diatasi dengan penyediaan alat potong buah yang memiliki kualitas baik oleh perusahaan sehingga pemanen mudah dan nyaman dalam melakukan pemotongan buah. Permasalahan pada alat pengangkutan TBS ke TPH dapat diantisipasi dengan melengkapi terlebih dahulu peralatan sebelum memulai pekerjaan.

\section{Kapasitas Panen}

Kapasitas panen adalah kemampuan pemanen dalam menurunkan buah dalam satu hari panen. Prestasi dan penghasilan pemanen dapat diukur melalui pencapaian kapasitas panen dan basis. Pemanen divisi 2 memiliki kapasitas panen yang berbeda. Pengamatan dilakukan terhadap 30 pemanen untuk melihat kapasitas panen per hari dan pencapaian basis pada setiap pemanen (Tabel $5)$.

Tabel 4. Jenis alat panen beserta spesifikasi dan kegunaannya

\begin{tabular}{|c|c|c|c|}
\hline No & Jenis & Spesifikasi & Kegunaan \\
\hline 1. & Dodos & $\begin{array}{l}\text { Lebar mata } 14 \mathrm{~cm} \text {, lebar tengah } 7 \mathrm{~cm} \text { dan panjang } 18 \\
\mathrm{~cm} .\end{array}$ & $\begin{array}{l}\text { Untuk potong buah pada tanaman } \\
\text { berusia } 5-8 \text { tahun. }\end{array}$ \\
\hline 2. & Egrek & $\begin{array}{l}\text { Panjang pangkal } 20 \mathrm{~cm} \text {, panjang pisau } 45 \mathrm{~cm} \text {, sudut } \\
\text { lengkung } 135 \text { derajat. }\end{array}$ & $\begin{array}{l}\text { Untuk potong buaah pada tanaaman berusia } \\
\text { di atas } 9 \text { tahun. }\end{array}$ \\
\hline 3. & Angkong & & $\begin{array}{l}\text { Untuk mengangkut buah dari kebun ke } \\
\text { TPH. }\end{array}$ \\
\hline 4. & Gancu & $\begin{array}{l}\text { Besi beton yang melengkung dan meruncing di } \\
\text { ujungnya. }\end{array}$ & Untuk menaikan TBS ke angkong. \\
\hline 5. & Kapak & & $\begin{array}{l}\text { Untuk memotong tangkai buah atau } \\
\text { membuang buah parthenocarpy. }\end{array}$ \\
\hline 6. & Karung & & Untuk alas brondolan di TPH \\
\hline 7. & Tojok & $\begin{array}{l}\text { Besi pipa yang runcing diujungnya dan terdapat } \\
\text { pegangan seperti huruf } \mathrm{T} \text { di pangkalnya. }\end{array}$ & Untuk mengangkat TBS ke truk. \\
\hline
\end{tabular}

Sumber: SOP Panen BGA (2016)

Tabel 5. Kapasitas panen di divisi 2 BKLE

\begin{tabular}{|c|c|c|c|c|c|c|c|c|}
\hline & \multicolumn{6}{|c|}{ Kapasitas pemanen (janjang per HK) } & \multirow{2}{*}{ Rata-rata janjang per HK } & \multirow{2}{*}{ Pencapaian basis (\%) } \\
\hline & $25 / 4$ & $26 / 4$ & $27 / 4$ & $28 / 4$ & $29 / 4$ & $30 / 4$ & & \\
\hline Rata-rata & 90 & 110 & 136 & 90 & 95 & 68 & 98 & 37 \\
\hline Basis & 128 & 128 & 128 & 128 & 91 & 128 & - & - \\
\hline
\end{tabular}


Rata-rata pemanen divisi 2 memiliki kapasitas 98 janjang per HK. Pencapaian terhadap kapasitas panen masih belum memenuhi standar perusahaan, pencapaian basis rata-rata hanya mencapai $37 \%$. Standart yang dibuat perusahaan terhadap kapasitas panen basis borong yaitu 128 janjang per HK kecuali pada hari jumat 91 janjang per HK. Hasil uji t-student (Tabel 6) menunjukkan bahwa rata - rata kapasitas panen untuk hari Senin, Selasa, Rabu, Kamis dan Sabtu sangat berbeda nyata dengan standar perusahaan 128 janjang. Hal ini menunjukkan bahwa rata-rata kapasitas panen tersebut belum sesuai dengan standar perusahaan 128 janjang. Rata - rata kapasitas panen untuk hari Jumat tidak berbeda nyata dengan standar perusahaan 91 janjang artinya rata-rata kapasitas panen tersebut sudah sesuai standar perusahaan.

Tabel 6. Hasil uji t-student rata-rata kapasitas panen terhadap standar perusahaan

\begin{tabular}{lccc}
\hline & $\begin{array}{c}\text { Rata-rata } \\
\text { kapasitas panen }\end{array}$ & $\begin{array}{c}\text { Standar } \\
\text { perusahaan }\end{array}$ & p-value \\
\hline Jumlah & 98.89 & 128 & $0.000^{* *}$ \\
janjang & 95.07 & 91 & $0.402^{\text {tn }}$ \\
\hline Keterangan: & Standar 128 janjang berlaku pada hari Senin, \\
& Selasa, Rabu, Kamis dan Sabtu, Standar 91 \\
& janjang berlaku pada hari Jumat, tn: tidak \\
& berbeda nyata pada uji-t taraf 5\%, $* *$ : sangat \\
& berbeda nyata pada uji-t taraf 5\%
\end{tabular}

Menurut Nugraha (2013) kelancaran kegiatan panen tidak hanya dipengaruhi oleh ketersediaan jumlah tenaga panen, keterampilan setiap tenaga panen juga berpengaruh terhadap produksi sebuah perusahaan kelapa sawit. Jumlah TBS yang dipanen dapat dipengaruhi oleh beberapa faktor, diantaranya umur, tingkat pendidikan dan lama kerja. Pada pengamatan kapasitas panen selanjutnya dilakukan uji $t$ student pada taraf 5\% dengan peubah usia dan lama kerja (Tabel 7). Pada peubah usia dikelompokkan menjadi 2 kelompok yaitu usia $\leq$ 30 tahun dan usia $>30$ tahun dengan ulangan tiga waktu pengamatan. Peubah berikutnya dilakukan terhadap kapasitas pemanen pada lama waktu telah bekerjanya pemanen yaitu $\leq 3$ tahun dan $>3$ tahun dengan ulangan tiga waktu pengamatan.

Tabel 7. Kapasitas panen pada tingkatan umur dan lama kerja terhadap rata-rata jumlah tandan per hari

\begin{tabular}{lcccc}
\hline Peubah & & $\begin{array}{c}\text { Rata-rata jumlah } \\
\text { tandan per hari }\end{array}$ & $\begin{array}{c}\mathrm{t}- \\
\text { hitung }\end{array}$ & Pr>t \\
\hline Umur & $\leq 30$ & 114 & -0.60 & $0.556^{\mathrm{tn}}$ \\
pemanen & $>30$ & 109 & & \\
Lama & $\leq 3$ & 102.6 & 1.54 & $0.135^{\mathrm{tn}}$ \\
kerja & $>3$ & 93.9 & & \\
\hline
\end{tabular}

Keterangan: tn: tidak berbeda nyata pada uji-t taraf 5\%
Pengujian uji t-student selanjutnya dilakukan untuk mengetahui perbedaan rata-rata kapasitas pemanen pada kelompok usia dan lama kerja. Hasil uji t-student yang dilakukan pada taraf 5\% didapatkan tidak berbeda nyata pada dua peubah tersebut (Tabel 6). Pada peubah umur pemanen rata-rata kapasitas panen pada umur $\leq$ 30 tahun yaitu 114 per janjang HK sedangkan pada umur > 30 tahun yaitu 109 janjang per HK. Pada peubah lama kerja pemanen rata-rata kapasitas panen pada lama kerja $\leq 3$ tahun yaitu 102.6 janjang per HK sedangkan pada lama kerja > 3 tahun yaitu 93.9 janjang per HK. Berdasarkan hasil uji $t$-student, peubah umur tidak berpengaruh terhadap produktivitas pemanen. Hal ini sesuai dengan hasil penelitian Trismiaty et al. (2008) yaitu umur dan tingkat pendidikan tidak berpengaruh nyata terhadap produktivitas pemanen. Hasil uji $t$-student pada peubah Lama kerja pemanen tidak berpengaruh nyata terhadap produktivitas pemanen. Hal ini tidak sesuai dengan Trismiaty et al. (2008) yang menyatakan bahwa lama kerja mempengaruhi produktivitas pemanen. Hasil yang didapatkan berbeda dengan literatur karena pengamatan yang dilakukan hanya mengamati lama kerja pemanen yang dimulai dari masuk kerja di BKLE.

\section{Mutu Buah}

Kegiatan panen yang baik adalah dengan melakukan evaluasi panen. Evaluasi panen yang dilakukan yaitu pegamatan terhadap mutu buah yang dihasilkan dalam satu seksi panen. BGA sangat memperhatikan mutu buah disetiap estate dan divisinya untuk memperoleh oil extraction rate (OER) sebesar $25.5 \%$. Pemeriksaan mutu buah menjadi hal yang wajib di BGA, pemeriksaan mutu buah yang dilakukan di BGA yaitu sebanyak 2 kali untuk memastikan buah yang dihasilkan sesuai standar yang telah ditetapkan perusahaan. Pemeriksaan mutu buah dilakukan di TPH oleh krani panen setiap divisi dan di pabrik oleh tim pemeriksa mutu buah dari Departemen Agronomy Quality Control (AQC) pada setiap hari. Pemeriksaan mutu yang dilakukan oleh AQC yaitu dengan pengambilan contoh 100 janjang secara acak pada salah satu dump truk pada setiap hari dan melakukan pemeriksaan mutu buah secara total dilakukan pada salah satu dump truk setiap divisi. Pemeriksaan mutu buah secara total dilakukan 3 kali dalam satu bulan. Kriteria mutu buah berdasarkan tingkat kematangan buah telah dibuat secara rinci dalam SOP (Tabel 8). 
Tabel 8. Kriteria mutu buah berdasarkan tingkat kematangan buah

\begin{tabular}{ll}
\hline \multicolumn{1}{c}{ Kriteria } & \multicolumn{1}{c}{ TPH dan loading ramp PKS } \\
\hline Mentah (Unripe) & 0 berondolan \\
Kurang matang (Under ripe) & $<2$ berondolan $/ \mathrm{kg}$ \\
Matang (Ripe) & 2 berondolan $/ \mathrm{kg}$ hingga $75 \%$ berondolan permukaan telah \\
Terlalu matang (Over ripe) & lepas \\
Janjang kosong (Empty bunch) & $>75 \%-90 \%$ berondolan telah lepas \\
\hline
\end{tabular}

Sumber : SOP Panen BGA (2016)

Hasil pengamatan mutu buah di TPH pada satu seksi panen selama 2 rotasi panen dengan pengambilan contoh sebanyak 100 janjang dikemukakan pada Tabel 9. Pada pengamatan mutu buah dilakukan uji $t$-student untuk membandingkan hasil rata-rata mutu buah terhadap standar perusahaan (Tabel 10).

Tabel 9. Hasil pengamatan mutu buah divisi 2 BKLE

\begin{tabular}{cccccc}
\hline & \multicolumn{5}{c}{ Mutu Buah } \\
\cline { 2 - 6 } Pengamatan & Ripe & Unripe & $\begin{array}{c}\text { Under } \\
\text { Ripe }\end{array}$ & $\begin{array}{c}\text { Over } \\
\text { Ripe }\end{array}$ & $\begin{array}{c}\text { Empty } \\
\text { bunch }\end{array}$ \\
\hline 1 & 85 & 0 & 9 & 6 & 0 \\
2 & 85 & 0 & 11 & 4 & 0 \\
3 & 82 & 0 & 14 & 4 & 0 \\
4 & 80 & 0 & 9 & 11 & 0 \\
5 & 85 & 0 & 13 & 2 & 0 \\
6 & 89 & 0 & 6 & 5 & 0 \\
7 & 89 & 0 & 9 & 2 & 0 \\
8 & 90 & 0 & 8 & 2 & 0 \\
9 & 88 & 0 & 5 & 7 & 0 \\
\hline Rata-rata & 86.1 & 0 & 9 & 4.9 & 0 \\
\hline
\end{tabular}

Tabel 10. Hasil uji t-student mutu buah rata-rata terhadap mutu buah standar perusahaan

\begin{tabular}{lccc}
\hline Mutu buah & Rata-rata & Standar perusahaan & $\mathrm{p}$-value \\
\hline Ripe & 86.1 & 85 & $0.456^{\mathrm{tn}}$ \\
Under ripe & 9 & 8 & $0.213^{\mathrm{tn}}$ \\
Over ripe & 4.9 & 7 & $0.054^{\mathrm{tn}}$ \\
\hline
\end{tabular}

Keterangan: tn: tidak berbeda nyata pada uji-t taraf 5\%

Berdasarkan Tabel 9 didapatkan hasil uji $t$ student pada mutu buah rata-rata terhadap standar perusahaan yaitu ripe, under ripe, dan over ripe tidak berbeda nyata. Hasil yang didapatkan memiliki arti bahwa mutu buah BKLE divisi 2 telah memenuhi standar perusahaan yang berlaku. Perusahan memiliki standar yang harus dicapai pada mutu buah yaitu buah mentah (unripe) $0 \%$, buah kurang matang (under ripe) $<8 \%$, buah masak (ripe) $>85 \%$, buah terlalu masak (over ripe) $<7 \%$ dan janjang kosong (empty bunch) $0 \%$. Pengawasan terhadap mutu buah telah dilakukan dengan baik oleh divisi 2 karena mutu buah yang dihaslkan sudah sesuai dengan standar perusahaan. Menurut Siahaan dan Erningpraja (2005), untuk menjamin perolehan TBS yang berkualitas, pengawasan mutu panen perlu dilakukan secara intensif dan reguler. Pengawasan tersebut antara lain rotasi panen dan pemanenan TBS pada tingkat kematangan yang optimal. Penanggulangan yang paling baik dalam mutu buah yaitu dengan pengawasan yang sesering mungkin di TPH dan hancak panen (Pahan, 2008).

\section{Kehilangan Hasil (Losses)}

Kehilangan hasil (losses) adalah salah satu kerugian yang didapatkan oleh perusahaan dalam suatu produksi. Produksi yang maksimal hanya akan dicapai jika kerugian atau kehilangan hasil dapat diminimalkan (Pahan, 2006). Kehilangan hasil di lapang bersumber dari buah mentah, buah masak yang tidak dipanen, brondolan yang tidak dikutip, buah yang sudah dipanen tidak diangkut ke TPH dan buah yang di TPH tidak diangkut atau terlambat ke PKS (BGA, 2010). Kegiatan menurunkan kehilangan hasil perlu dilakukan dengan memberikan arahan dan melakukan pengawasan pada saat apel pagi maupun pada saat pelaksanaan panen. Hasil pengamatan yang dilakukan terhadap kehilangan hasil yaitu melalui pemeriksaan mutu hancak (Tabel 11) dan mutu TPH (Tabel 12). Pada pengamatan kehilangan hasil dilakukan uji t-student untuk membandingkan hasil rata-rata mutu buah terhadap standar perusahaan (Tabel 13).

Kehilangan hasil adalah salah satu hal yang sangat dihindari karena dengan adanya kehilangan hasil maka akan menyebabkan kerugian pada perusahaan. BGA dalam menanggulangi dan mencegah kehilangan hasil maka membentuk Departemen Agronomy Quality Control (AQC). Salah satu tugas AQC adalah memastikan atau mengecek keadaan lapang berupa mutu hancak dan mutu TPH tidak ada losses. AQC melakukan pengecekan mutu hancak dan mutu TPH 2 - 3 kali dalam sebulan.

Berdasarkan uji $t$-student pada perbandingan kehilangan hasil brondolan per ha dan buah tinggal per ha terhadap standar perusahaan didapatkan hasil tidak berbeda nyata, sedangakan pada uji t-student terhadap kehilangan hasil brondolan di TPH didapatkan hasil yang berbeda nyata. Hasil ini memiliki arti bahwa kehilangan hasil yang berada di lapang masih belum sesuai standar yang ditetapkan oleh 
Tabel 11. Kehilangan hasil pada mutu hancak

\begin{tabular}{cccccccc}
\hline Pengamatan & $\begin{array}{c}\text { Tanaman } \\
\text { dicek }\end{array}$ & $\begin{array}{c}\text { Janjang } \\
\text { dipanen }\end{array}$ & $\begin{array}{c}\text { Buah } \\
\text { tinggal }\end{array}$ & Tanaman & $\begin{array}{c}\text { Brondolan } \\
\text { tinggal }\end{array}$ & $\begin{array}{c}\text { Buah tinggal } \\
\text { per ha }\end{array}$ & $\begin{array}{c}\text { Brondolan } \\
\text { tinggal per ha }\end{array}$ \\
\hline 1 & 576 & 121 & 0 & 120 & 180 & 0 & 42.50 \\
2 & 469 & 89 & 0 & 89 & 103 & 0 & 29.87 \\
3 & 672 & 132 & 4 & 128 & 145 & 0.81 & 29.35 \\
4 & 630 & 84 & 2 & 82 & 95 & 0.43 & 20.51 \\
5 & 546 & 74 & 0 & 74 & 120 & 0 & 29.89 \\
6 & 487 & 58 & 1 & 58 & 97 & 0.28 & 27.09 \\
7 & 402 & 64 & 0 & 63 & 101 & 0 & 34.17 \\
8 & 588 & 93 & 4 & 93 & 124 & 0.93 & 28.68 \\
9 & 518 & 78 & 0 & 78 & 82 & 0 & 21.53 \\
\hline Rata-rata & 511.93 & 83.07 & 0.93 & 82.50 & 105.07 & 0.52 & 29.29 \\
\hline
\end{tabular}

Tabel 12. Kehilangan hasil pada mutu TPH

\begin{tabular}{cccc}
\hline Pengamatan & $\begin{array}{c}\text { TPH } \\
\text { yang } \\
\text { dicek }\end{array}$ & $\begin{array}{c}\text { Brondolan } \\
\text { tinggal }\end{array}$ & $\begin{array}{c}\text { Rata-rata } \\
\text { brondolan } \\
\text { tinggal per TPH }\end{array}$ \\
\hline 1 & 10 & 20 & 2.0 \\
2 & 10 & 17 & 1.7 \\
3 & 10 & 5 & 0.5 \\
4 & 10 & 5 & 0.5 \\
5 & 10 & 28 & 2.8 \\
6 & 10 & 11 & 1.1 \\
7 & 10 & 35 & 3.5 \\
8 & 10 & 9 & 0.9 \\
9 & 10 & 41 & 4.1 \\
\hline Rata-rata & 10 & 19 & 1.9 \\
\hline
\end{tabular}

Tabel 13. Hasil uji t-student kehilangan hasil ratarata terhadap kehilangan hasil standar perusahaan

\begin{tabular}{lccc}
\hline Kehilangan hasil & Rata-rata & $\begin{array}{c}\text { Standar } \\
\text { perusahaan }\end{array}$ & p-value \\
\hline Brondolan per ha & 29.29 & 25 & $0.085^{\mathrm{tn}}$ \\
Buah tinggal per ha & 0.52 & 0 & $0.060^{\mathrm{tn}}$ \\
Brondolan per TPH & 1.90 & 3 & $0.036^{*}$ \\
\hline
\end{tabular}

Keterangan: $*$ = Berbeda nyata pada taraf $5 \%$, tn: tidak berbeda nyata pada uji-t taraf $5 \%$

perusahaan. Standar yang sudah ditetapkan oleh perusahaan yaitu untuk buah masak yang tidak dipanen harus tidak ada, untuk brondolan tinggal atau yang tidak dikutip harus berjumlah 25 butir per ha serta untuk brondolan tinggal di TPH harus berjumlah minimal 3 butir per TPH. Menurut Lubis (2008) pemeriksaan kebersihan di lapang sangat perlu dilakukan supaya tidak adanya ancak yang tertinggal atau tandan matang yang tertinggal. Penyelesaian masalah terhadap losses tersebut bisa diatasi dengan pemberlakuan sanksi dan denda yang ketat sehingga pemanen akan lebih teliti dalam bekerja, selain itu perlunya pemberian insentif bagi pemanen terbaik yang memiliki jumlah losses yang sedikit sehingga para pekerja dapat saling bersaing dalam menjadi yang terbaik. Insentif yang akan diberikan tersebut dapat berasal dari pembayaran denda pemanen.

\section{Transportasi Buah}

Manajemen transportasi merupakan salah satu faktor penting dalam mengumpulkan dan mengangkut hasil panen menuju pabrik dengan kerusakan sekecil mungkin. Menurut Suryono (2012) faktor-faktor yang mempengaruhi kelancaran transportasi TBS adalah organisasi potong buah, kondisi jalan, jenis alat transportasi, perawatan kendaraan transportasi, pengoperasian kendaraan transportasi dan kelancaran pengolahan di pabrik. Kegiatan transportasi di BGA dikelola oleh bagian transportasi produksi dan reparasi (TRAKSI). Traksi bertugas mengatur semua transportasi yang ada di kebun, pemeliharaan dan perbaikan alat, alokasi kendaraan dan alat berat, dan sebagai pendukung serta membuat, memperbaiki dan merawat jalan.

Transportasi panen dilakukan dengan menggunakan kendaraan dengan jenis kendaraan dump truk dengan kapasitas $7500 \mathrm{~kg}$, kegiatan transportasi dimulai ketika buah sudah dikeluarkan semua oleh pemanen dan diletakkan di TPH, kemudian krani transpor berkoordinasi kepada krani buat untuk pengangkutan buah dari TPH ke dump truk. Buah yang sudah diberi tanda dan di periksan mutu buahnya oleh krani panen harus segera dimuat ke dump truk dan dikirim ke pabrik untuk mendapatkan mutu buah yang baik. Tenaga kerja yang digunakan untuk transportasi yaitu terdiri dari satu krani transpor, satu pengemudi dan 3 tenaga bongkar muat. Buah dan brondolan yang ada di TPH harus diangkut semua ke PKS tanpa ada yang tercecer. Pengiriman buah ke PKS harus disertai surat pengantar buah (SPB). SPB dibuat oleh krani transpor. Satu SPB terlampir 4 lembar yang setiap lembarnya harus terdapat barcode, lampiran ini diberikan kepada pihak pabrik, kebun, divisi dan krani transpor.

Transportasi pengiriman buah di divisi 2 BKLE menggunakan 2 unit dump truck pada pa- 
Tabel 14. Hasil uji t-student kehilangan hasil rata-rata terhadap kehilangan hasil standar perusahaan

\begin{tabular}{ccccccc}
\hline Ulangan & $\begin{array}{c}\text { Janjang dikirim } \\
\text { (janjang) }\end{array}$ & $\begin{array}{c}\text { Waktu muat } \\
\text { (menit) }\end{array}$ & $\begin{array}{c}\text { Waktu tempuh } \\
\text { ke PKS }\end{array}$ & $\begin{array}{c}\text { Kecepatan rata- } \\
\text { rata }\left(\mathrm{km} \mathrm{jam}^{-1}\right)\end{array}$ & $\begin{array}{c}\text { Berat } \\
\text { muatan }(\mathrm{kg})\end{array}$ & $\begin{array}{c}\text { Tenaga } \\
\text { BM }\end{array}$ \\
\hline 1 & 691 & 115 & 10 & 15 & 7290 & 3 \\
2 & 631 & 87 & 6 & 17 & 6520 & 3 \\
3 & 664 & 95 & 9 & 17 & 6318 & 3 \\
\hline Rata-rata & 662 & 99 & 8.33 & 16.33 & 6709 & 3 \\
\hline
\end{tabular}

nen normal. Tenaga bongkar muat terdapat 2 kelompok dalam satu kelompok terdapat 3 orang. Jarak antara PKS dengan divisi 2 yaitu $2 \mathrm{~km}$. Pengamatan dilakukan terhadap waktu muat TBS ke dump truk berkapasitas $7.500 \mathrm{~kg}$, jumlah buah yang dikirim, waktu yang dibutuhkan untuk tiba ke PKS, kecepatan rata-rata, jumlah tenaga bongkar muat, serta tonase yang dimuat, (Tabel 14).

Kegiatan terakhir dalam pemanenan yaitu trasportasi buah dari TPH ke PKS. Menurut Alfiah dan Susanto (2015), salah satu faktor eksternal yang menyebabkan peningkatan kadar ALB yang relatif tinggi dalam minyak kelapa sawit adalah keterlambatan dalam pengumpulan dan pengangkutan buah. Perawatan jalan adalah salah satu faktor penting dalam pengangkutan buah, semakin baik kondisi jalan maka akan semakin cepat buah sampai ke pabrik.

Pengangkutan buah dari TPH ke PKS di BKLE divisi 2 menggunakan 2 unit dump truck dengan kapasitas $7.500 \mathrm{~kg}$. Pabrik yang dituju dalam pengantaran buah adalah Sungai Cempaga Mill (SCMM). Berdasarkan pengamatan yang dilakukan waktu muat rata-rata yaitu 99 menit dengan waktu tempuh rata-rata adalah 8,33 menit. Tonase dalam pengiriman selalu kurang dari kapasitas dump truck yaitu dengan rata-rata 6.709 kg karena ketinggian buah pada dump truk yaitu hanya dilakukan susun 1 dengan mengejar target pengiriman buah secepatnya ke PKS, selain itu dengan memuat kurang dari $7.500 \mathrm{~kg}$ dapat meminimalisir kerusakan alat angkut dan jalan. Tenaga kerja bongkar muat telah sesuai dengan standar perusahaan yaitu 3pekerja, berkurangnya pekerja bongkar muat dari standar maka waktu muat buah akan semakin lama.

Kendala yang terdapat pada kegiatan transportasi panen adalah pertama penggunaan unit secara bergantian untuk kegiatan lain seperti pengangkutan pupuk anorganik atau pengangkutan pupuk organik, sehingga kegiatan muat buah dimulai terlambat dari jadwal seharusnya. Kendala kedua masih terdapatnya

kondisi jalan yang rusak, sehingga pengantaran buah ke PKS terhambat. Hal ini dapat dihindari dengan pembuatan jadwal penggunaan unit sehingga dapat dialokasikan pada waktunya dan kondisi buah yang dikirim ke pabrik tidak mengalami restan, perawatan jalan harus dilakukan secara rutin. Secara keseluruhan kegiatan transportasi di divisi 2 BKLE sudah terlaksana dengan baik.

\section{KESIMPULAN}

Kegiatan penelitian memberikan pengetahuan dan pengalaman baik secara teknis maupun manajerial dalam mengelola perkebunan kelapa sawit. Manajemen pemanenan kelapa sawit di divisi 2 BKLE sudah berjalan cukup baik, tetapi masih terdapatnya SOP yang belum diterapkan oleh pekerja. Persentase varian tonase yang masih tinggi. Kebutuhan tenaga panen sudah sesuai SOP perusahaan. Penggunaan alat pelindung diri yang masih perlu ditingkatkan. Kapasitas panen tergolong rendah yaitu hanya $37 \%$ dalam mencapai basis. Mutu buah yang dihasilkan sudah sesuai SOP perusahaan. Kehilangan hasil yang terdapat di lapang masih belum sesuai SOP perusahaan yang meliputi mutu ancak dan mutu TPH. Transportasi buah sudah berjalan cukup baik.

\section{DAFTAR PUSTAKA}

Andoko, A., Widodoro. 2013. Berkebun Kelapa Sawit "Si Emas Cair". Agro Media Pustaka, Jakarta.

[BGA] Bumitama Gunajaya Agro. 2010. Pedoman Teknis Agronomis Kelapa Sawit (Elaeis guineensis Jacq.). BGA Group Plantations, Jakarta.

[Ditjenbun] Direktorat Jenderal Perkebunan. 2014. Perkembangan luas areal perkebunan 2010-. [internet]. [diunduh 201529 Desember]. Tersedia pada http://ditjenbun.deptan.go.id

Fauzi, Y., Widyastuti, Y.E., Satyawibawa, I., Hartono, R.. 2008. Kelapa Sawit: Budidaya Pemanfaatan Hasil dan Limbah Analisis Usaha dan Pemasaran Edisi Revisi. Penebar Swadaya, Jakarta. 
Fadli, Lukman, M., Sutarta, E.S., Darmosarkoro, W., Purba, P., Ginting, E.N. 2006. Seri Buku Saku 22: Panen Pada Tanaman Kelapa Sawit. Pusat Penelitian Kelapa Sawit Oil Palm Research Institute, Medan. Hal 51.

Lubis, A.U. 1992. Kelapa Sawit (Elaeis guineensis Jacq.) di Indonesia. Pusat Penelitian Perkebunan Marihat, Medan.

Miranda, R.R. 2009. Manajemen panen tanaman kelapa sawit (Elaeis guineensis Jacq.) di PT. Gunung Kemasan Estate, Minamas Plantation, Pulau Laut, Kalimantan Selatan [Skripsi]. Institut Pertanian Bogor. Bogor.

Nugraha, Y.P. 2013. Manajemen panen kelapa sawit (Elaeis Guineensis Jacq.) di Kebun Sei Air Hitam, PT Perdana Inti Sawit Perkasa I, Riau [Skripsi]. Institut Pertanian Bogor. Bogor.

Pahan, I. 2008. Kelapa Sawit: Manajemen Agribisnis dari Hulu hingga Hilir CetakanII. Penebar Swadaya, Jakarta.
[PPKS] Pusat Penelitian Kelapa Sawit. 2006. Budidaya Kelapa Sawit. Pusat Penelitian Kelapa Sawit, Medan.

Siahaan, D., Erningpraja, L. 2005. Penerapan good agriculture practice dan good manufacture practice dalam meningkatkan mutu dan keamanan pangan minyak kelapa sawit. $J$. Penelitian Kelapa Sawit. 13(3): 109- 118.

Suma'mur, P.K. 1996. Higene Perusahaan dan Kesehatan Kerja. PT. Toko Gunung Agung , Jakarta.

Suryono A. 2012. Pengelolaan pemanenan kelapa sawit (Elaeis guineensis Jacq.) di PT Aneka Intipersada Pinang Sebatang Estate, Kabupaten Siak, Riau [Skripsi]. Institut Pertanian Bogor. Bogor.

Trismiaty, Listyani, dan Mubaraq T.Z. 2008. Manajemen tenaga kerja kelapa sawit di PT Perkebunan III Kebun Aek Nabara Selatan Labuhan Batu Sumatera Utara. Buletin Ilmiah Instiper. 15(1):15-23. 